УДК 556.531.4:550.84.094

\title{
УСЛОВИЯ ТРАНСФОРМАЦИИ КОММУНАЛЬНО-БЫТОВЫХ СТОЧНЫХ ВОД В БОЛОТНЫХ ЭКОСИСТЕМАХ (НА ПРИМЕРЕ ОБСКОГО БОЛОТА, ЗАПАДНАЯ СИБИРЬ)
}

\author{
Иванова Ирина Сергеевна', \\ IvanovalS_1986@mail.ru
}

\author{
Савичев Олег Геннадьевич², \\ OSavichev@mail.ru
}

\section{Солдатова Евгения Александровна ${ }^{3}$, 2a61@mail.ru}

\author{
Корнеев Дмитрий Сергеевич 4 , \\ mitay2580@mail.ru
Гусева Наталья Владимировна², gusevanv@tpu.ru
Смирнова Наталья Александровна², smirnova@hw.tpu.ru

\author{
Наливайко Нина Григорьевна², \\ nng@tpu.ru \\ 1 Томский филиал Института нефтегазовой геологии и геофизики им. А.А. Трофимука СО РАН, \\ Россия, 634055, г. Томск, пр. Академический, 4. \\ 2 Национальный исследовательский Томский политехнический университет, \\ Россия, 634050, г. Томск, пр. Ленина, 30. \\ 3 Институт геохимии и аналитической химии им. В.И. Вернадского РАН, \\ Россия, 119991, г. Москва, ул. Косыгина, 19. \\ 4 Югорский государственный университет, \\ Россия, 628012, г. Ханты-Мансийск, ул. Чехова, 16.
}

\begin{abstract}
Актуальность. Проблема охраны и использования болот является весьма актуальной во всем мире, в том числе в Западной Сибири, на территории которой добывается значительная часть углеводородного сырья в Российской Федерации, что сопровождается изменением окружающей среды, в том числе и болотных экосистем. В свою очередь, это определяет необходимость разработки методологии и технологий природоохранных мероприятий на болотах, подвергающихся антропогенному воздействию. В рамках такой методологии требуется достоверная оценка изменений состояния болотной экосистемы под влиянием поступления веществ антропогенного происхождения.

Цель: анализ и обоснование условий трансформации коммунально-бытовых сточных вод в низинном болоте на примере типичного для Западной Сибири евтрофного Обского болота.

Методы. Химический и микробиологический составы вод и торфоов исследовались в Проблемной научно-исследовательской лаборатории гидрогеохимии (ТПУ), зарегистрированной в Системе аналитических лабораторий Госстандарта России. Для проведения полного химического анализа использовались традиционные методы. Микробиологический анализ производили после отбора проб, как правило, в течение суток. Доставка проб в лабораторию осуществлялась в сумке-холодильнике. Для выявления микроорганизмов использовали жидкие и твердые элективные питательные среды. Микрокомпонентный состав определялся при помощи масс-спектрометрического метода с индуктивно-связанной плазмой (ICP-MS). Cтруктурногрупповой состав растворенных органических веществ изучался методом хромато-масс-спектрометрии в лаборатории разработки месторождений нефти и газа (ТПУ). Для изучения гидрогеохимических процессов применялись статистические методы и математическое моделирование.

Результаты и выводы. Установлено, что болотные воды относительно ПДК характеризуются повышенными содержаниями органических веществ, продуктов их трансформации, а также некоторых химических элементов, с которыми органические вещества способны образовывать комплексы. Среди растворенных органических соединений в болотных водах доминируют сложные эфиры, карбоновые кислоты, которые способствуют не только накоплению некоторых элементов (Ni, Ba) в водах, но и развитию микроорганизмов. Показано, что накопление веществ, поступающих с коммунально-бытовыми сточньми водами с. Мельниково, происходит в основном на границе деятельного и инертного горизонтов торффяной залежи. Показано, что сброс коммунально-бытовых сточных вод в болото (с. Мельниково) не приводит к существенному изменению химического состава болотных вод, а антропогенное воздействие лимитируется микробиологическими и геохимическими условиями в болоте. На основе полученных данных предложено скорректировать природоохранные мероприятия, ограничивающие рост заболоченности территорий за счет увеличения лесных угодий вследствие осушительных мелиораций и дополнительного внесения соединений азота и кальция, входящих в состав сточных вод жилищно-коммунального хозяйства и нефтегазодобывающего комплекса.
\end{abstract}

\section{Ключевые слова:}

Сточные воды, химический состав, разработка методологии и технологий, самоочищение коммунально-бытовых сточных вод, Обское низинное болото. 


\section{Введение}

Проблема охраны и использования болот является весьма актуальной во всем мире в целом и в Западной Сибири в частности. Причем в последнем случае имеется ярко выраженная специфика. Во многих регионах мира наблюдается деградация болот (вследствие изменений климата, добычи торфа, мелиорации и последующего освоения осушенной территорий [1-4]), а в Западной Сибири - прогрессирующее заболачивание (вертикальный прирост до 1,8 мм/год, в среднем - около 1 мм/год) на фоне повышения уровней подземных вод (уменьшения глубины залегания) и техногенного подтопления в процессе функционирования нефтегазового комплекса [5-11].

Соответственно, возникают специфичные для Западной Сибири требования к охране и использованию болот, обусловленные тем, что хозяйственная деятельность, вопервых, не может быть остановлена, но должна учитывать региональные природные условия, а во-вторых, часто приводит не к деградации, а (в условиях слабой дренированности и избыточного увлажнения) к расширению болот $[12,13]$. В свою очередь, это определяет необходимость разработки методологии и технологий природоохранных мероприятий на болотах, на территории которых проводится добыча нефти и газа, размещение амбаров отходов бурения, прочих производственных объектов, включая дороги и трубопроводы. В рамках такой методологии требуется достоверная оценка изменений состояния болотной экосистемы под влиянием поступления веществ антропогенного происхождения [14].

Далее используется термин «загрязняющие вещества», но при этом полагается, что «загрязняющими веществами» некорректно называть вещества по признаку одного лишь присутствия в водных объектах в концентрациях, превышающих предельно допустимые значения (ПДК), установленные в Российской Федерации или где-либо еще. Для признания этих веществ «загрязняющими» необходимо доказать, что их нахождение в водах обусловлено влиянием именно хозяйственной деятельности (с учетом требований [15]), что в условиях методической неопределенности в ряде случаев приводит к признанию «антропогенным» любое воздействие, приводящее к превышению ПДК. Однако методика определения последних предполагает вполне определенные лабораторные условия, очень часто сильно отличающиеся от состояний, наблюдаемых вне участков явно антропогенного воздействия. В результате возникает неопределенность оценки генезиса веществ в водном объекте и, следовательно, разработки мероприятий по их охране.

Особенно остро данный вопрос стоит в случае торфяных болот, поскольку торф - органическая горная порода, сформировавшаяся в результате отмирания и неполного распада болотных растений в условиях избыточного увлажнения при недостатке кислорода [16], - является источником поступления в реки, озера и грунтовые воды большого количества органических веществ, продуктов их трансформации и соединений с металлами. По этой причине в болотных экосистемах (без их ликвидации) невозможно добиться выполнения нормативов качества, установленных для прочих водных объектов, и, следовательно, гораздо сложнее спланировать природоохранные мероприятия и оценить их эффективность.

С учетом этого в Томском политехническом университете (ТПУ) в течение более чем двух десятилетий проводится исследование влияния антропогенных факторов на эколого-геохимическое состояние болотных вод и торфов с целью разработки научных основ мелиорации и рекультивации болот Западной Сибири. Ниже (в развитие работы [17]) представлены результаты одного из этапов этого исследования, в рамках которого были рассмотрены условия трансформации коммунально-бытовых сточных вод в низинном болоте. Соответственно, основной упор был сделан на анализ ранее недостаточно изученных аспектов изменения в загрязненных болотных водах микрофлоры, неорганических и, особенно, растворенных органических микропримесей. Основные сведения о химическом составе болотных вод и торфов Обского болота приведены в [17-19], а дополнительные сведения о составе торфов и общем состоянии болот рассматриваемой территории - в [13, 14, 20-22].

\section{Объект и методика исследования}

В качестве объекта исследования выбраны участки долинного евтрофного Обского болота, расположенного в Томской области в левобережной части долины реки Обь общей длиной около 104 км, шириной 1,5-7,0 км и мощностью торфяной залежи в среднем около 3,2 м. Торфа низинные, со степенью разложения $34 \%$ и зольностью 28-29\%. Более подробная информация об Обском болоте приведена в [17-19]. Один из участков (в с. Мельниково - административном центре Шегарского района Томской области) рассматривается как антропогенно нарушенный, а другой (у с. Нащеково, расположенного южнее с. Мельниково и выше по уклону реки Обь) - как фоновый. Преобладающий тип биогеоценоза на обоих участках - березово-тростниковый. Наблюдения за химическим составом болотных и сточных вод проводились в ТПУ и компании «Томскгеомониторинг» под руководством и/или при непосредственном участии авторов в 2002, 2003, 2004, 2012, 2013, 2018 гг., но наиболее полные данные о пространственном изменении гидрогеохимических показателей получены в 2012 и 2018 гг. В пределах нарушенного участка выделены створы (перпендикулярно суходолу) собственно выпуска сточных вод жилищнокоммунального хозяйства с. Мельниково (в табл. 2 обозначен индексом «І») и в 50 м выше дороги с. Мельниково - с. Старая Шегарка (II). На фоновом участке в 2012 г. отбор проб проводился в черте с. Нащеково (III), а в 2018 г. - в 5 км южнее (IV).

Методика исследования включала в себя:

1) отбор (в ноябре 2018 г.) и анализ проб болотной воды и торфов Обского болота у сел Нащеково и Мельниково, включая определение химического (с использованием масс-спектрометрического метода с индуктивно связанной плазмой) и микро- 
биологического состава; местоположение пунктов отбора проб показано на рис. 1 (более подробная информация в [17]); методика отбора и анализа проб идентична методике, изложенной в [20], микробиологические исследования выполнены по методикам, изложенным в [23, 24], методика изучения растворенных органических соединений изложена в [25-28]. Данная методика предназначена для обзорного определения растворенных органических соединений (исключая фульво- и гуминовые кислоты) и основана на получении хлороформных концентратов трехступенчатой экстракцией хлороформом при значениях рН 2, 7, 11, которые далее были изучены методом хромато-массспектрометрии (ГХ-МС) [29-31].

2) обобщение и анализ данных, полученных в 2018 г. и ранее, в том числе и анализ изменений химического состава болотных вод по мере удаления от суходола и выпуска сточных вод, а в районе села с. Мельниково - изменения состава кислотных вытяжек из торфов в вертикальном разрезе болота;

3) оценку насыщенности болотных вод относительно ряда минералов и органоминеральных соединений на основе расчета индексов насыщения SI (1), по методике, описанной в предыдущих работах авторов:

$$
S I=\lg \Pi \text { А }-\lg K_{n e q},
$$

где ПА - произведение активностей группы веществ; $K_{n e q}$ - константа неустойчивости. Перечень изученных химических реакций приведен в табл. 1.

Исследование полученных данных включало процедуры корреляционного и регрессионного анализа при уровне значимости 5 \% и соблюдении условий $|s|>2 \cdot \delta_{s}$ и $|r|>0,7$ [32], где $s$ и $\delta_{s}-$ статистика (коэффициент корреляции $\mathrm{r}$ или регрессии $k_{r, j}$ ) и погрешность ее определения; погрешность определения коэффициента корреляции $\delta_{\text {r }}$ оценена по уравнению (2):

$$
\delta_{r} \approx \frac{1-r^{2}}{\sqrt{N-2}}
$$

где $N$ - объем выборки.

\section{Результаты исследования и их обсуждение}

Воды Обского болота на фоновом участке у с. Нащеково характеризуются средними значениями $\mathrm{pH} 7,58 \pm 0,09$ и суммы главных ионов $\Sigma_{\text {ги }} 559,4 \pm 14,3$

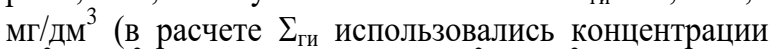
$\mathrm{Ca}^{2+}, \mathrm{Mg}^{2+}, \mathrm{Na}^{+}, \mathrm{K}^{+}, \mathrm{HCO}_{3}{ }^{-}, \mathrm{CO}_{3}{ }^{2-}, \mathrm{SO}_{4}{ }^{2-}, \mathrm{Cl}^{-}$), повышенными относительно ПДК содержаниями $\mathrm{NH}_{4}^{+}$ $\left(2,57 \pm 2,48 \mathrm{мг} /\right.$ дм $\left.^{3}\right)$ и достаточно высокими (по сравнению с реками региона) содержаниями органических веществ (например, фульвокислот, обнаруженных в ноябре 2012 г. в количестве 20,70 мг/дм ${ }^{3}$ [17, 19]). В районе с. Мельниково на границе суходола и болота в течение ряда десятилетий производится сброс коммунально-бытовых сточных вод (сухой остаток 646-1226 мг/дм³ ; определение концентраций $\mathrm{Ca}^{2+}, \mathrm{Mg}^{2+}, \mathrm{Na}^{+}, \mathrm{K}^{+}, \mathrm{HCO}_{3}^{-}, \mathrm{CO}_{3}{ }^{2-}$ не проводилось, но возможно использование приближенного соотношения [сухой остаток] $\left./ \Sigma_{\text {ги }} 0,8\right)$, что привело к последовательному уменьшению при удалении от выпуска

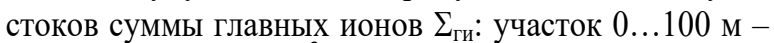
$1249,0 \pm 166,3$ мг/дм ${ }^{3}$; участок $101 \ldots 250$ м $1120,1 \pm 139,7$ мг/дм ${ }^{3}$; участок $251 \ldots 700$ м $1095,0 \pm 105,5$ мг/дм ${ }^{3}$.

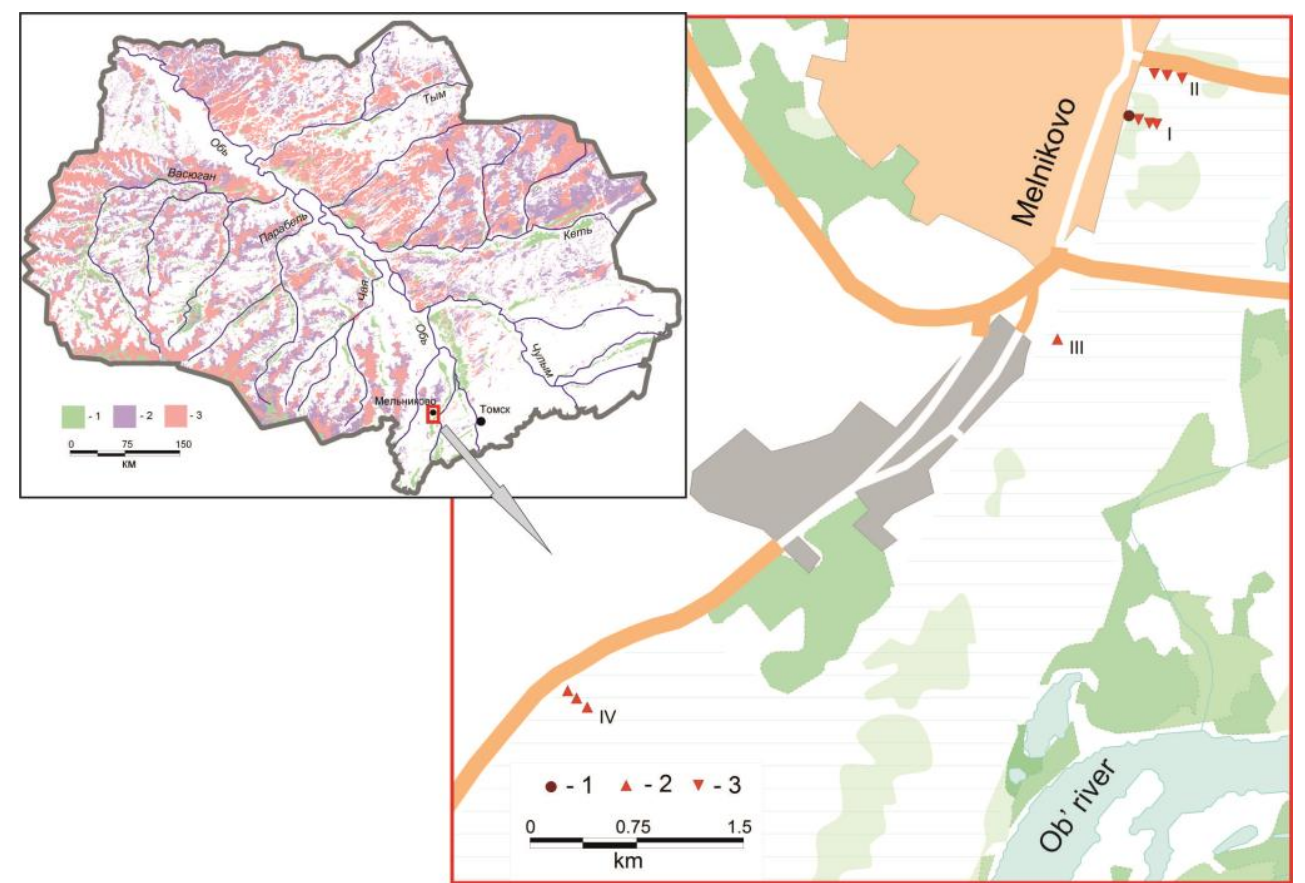

Pис. 1. Схема размещения пунктов наблюдений за химическим составом вод Обского болота у с. Мельниково: 1 - сточные воды МУП «Комхоз» с. Мельниково; 2 - фоновый участок; 3 - участок загрязнённого болота

Fig. 1. Scheme of sampling points location in the Obskoe bog near Melnikovo: 1 -wastewater; 2 - points characterizing geochemical background (natural territory); 3 - polluted area of the bog (anthropogenic territory) 
Таблица 1. Перечень изученных реакций и статистически значимые коэффициенты корреляиии между суммой главных ионов и значениями индексов насыщения

Table 1. List of studied reactions and statistically significant correlation coefficients between the sum of the main ions and the saturation indices

\begin{tabular}{|c|c|c|c|c|c|c|c|c|c|c|c|}
\hline № & Реакция/Reaction & $r\left(\sum_{\text {ги }}\right)$ & $r\left(\mathrm{Ca}^{2+}\right)$ & $r\left(\mathrm{Mg}^{2+}\right)$ & $r\left(\mathrm{Na}^{+}\right)$ & $r\left(\mathrm{~K}^{+}\right)$ & $r\left(\mathrm{HCO}_{3}^{-}\right)$ & $r\left(\mathrm{Cl}^{-}\right)$ & $r\left(\mathrm{SO}_{4}{ }^{2-}\right)$ & $r(\mathrm{Si})$ & $r(\Pi \mathrm{O})$ \\
\hline 1 & $\mathrm{CaCO}_{3 \text { calcite }}=\mathrm{Ca}^{2+}+\mathrm{CO}_{3}{ }^{2-}$ & 0,63 & - & - & 0,56 & 0,63 & 0,63 & 0,63 & 0,63 & - & - \\
\hline 2 & $\mathrm{CaCO}_{3 \text { calcite }}+\mathrm{CO}_{2}+\mathrm{H}_{2} \mathrm{O}=\mathrm{Ca}^{2+}+2 \cdot \mathrm{HCO}_{3}^{-}$ & $-0,60$ & 0,49 & $-0,53$ & $-0,56$ & $-0,57$ & $-0,57$ & $-0,57$ & $-0,57$ & - & - \\
\hline 3 & $\mathrm{CaMg}\left(\mathrm{CO}_{3}\right)_{2 \text { dolomite }}=\mathrm{Ca}^{2+}+\mathrm{Mg}^{2+}+2 \cdot \mathrm{CO}_{3}{ }^{2-}$ & 0,77 & - & 0,63 & 0,72 & 0,76 & 0,76 & 0,76 & 0,76 & 0,48 & - \\
\hline 4 & $\begin{array}{c}\mathrm{CaMg}\left(\mathrm{CO}_{3}\right)_{2 \text { dolomite }}+2 \cdot \mathrm{CO}_{2}+2 \cdot \mathrm{H}_{2} \mathrm{O}= \\
\mathrm{Ca}^{2+}+\mathrm{Mg}^{2+}+4 \cdot \mathrm{HCO}_{3}^{-}\end{array}$ & $-0,54$ & - & - & $-0,49$ & $-0,51$ & $-0,51$ & $-0,51$ & $-0,51$ & - & - \\
\hline 5 & $\mathrm{Ca}(\Gamma \mathrm{K})=\mathrm{Ca}^{2+}+\Gamma \mathrm{K}$ & $-0,85$ & 0,93 & $-0,67$ & $-0,86$ & $-0,84$ & $-0,84$ & $-0,84$ & $-0,84$ & $-0,87$ & $-0,80$ \\
\hline 6 & $\mathrm{H}_{2} \mathrm{O}=\mathrm{H}_{4} \mathrm{SiO}_{4}{ }^{0}$ & 0,90 & $-0,73$ & 0,76 & 0,94 & 0,90 & 0,90 & 0,90 & 0,90 & 0,99 & 0,71 \\
\hline 7 & $\begin{array}{c}2 \cdot \mathrm{NaAlSi}_{3} \mathrm{O}_{8} \text { albite } \\
\mathrm{Al}_{2} \mathrm{Si}_{2} \mathrm{O}_{7} \cdot 2 \cdot 2 \cdot \mathrm{H}_{2} \mathrm{O}_{\text {kaalinite }}+2 \cdot \mathrm{H}_{2} \mathrm{O}+2 \cdot \mathrm{CO}_{2}= \\
+2 \cdot \mathrm{HCO}_{3}{ }^{-}+4 \cdot \mathrm{H}_{4} \mathrm{SiO}_{4}{ }^{0}\end{array}$ & 0,51 & - & - & 0,59 & 0,52 & 0,52 & 0,52 & 0,52 & 0,65 & - \\
\hline 8 & $\begin{array}{r}3 \cdot \mathrm{KAlSi}_{3} \mathrm{O}_{8 \mathrm{mi}} \\
\mathrm{KAl}_{3} \mathrm{Si}_{3} \mathrm{O}_{10} \mathrm{OH}_{2} \\
\end{array}$ & 0,93 & $-0,68$ & 0,78 & 0,96 & 0,94 & 0,94 & 0,94 & 0,94 & 0,94 & 0,67 \\
\hline 9 & $\begin{array}{c}2 \cdot \mathrm{KAl}_{3} \mathrm{Si}_{3} \mathrm{O}_{10} \mathrm{OH}_{2} \text { muscovite }+2 \cdot \mathrm{H}^{+}+3 \cdot \mathrm{H}_{2} \mathrm{O}= \\
\quad 3 \cdot \mathrm{Al}_{2} \mathrm{Si}_{2} \mathrm{O}_{7} \cdot 2 \cdot \mathrm{H}_{2} \mathrm{O}_{\text {kaolinite }}+2 \cdot \mathrm{K}^{+}\end{array}$ & 0,86 & $-0,56$ & 0,74 & 0,88 & 0,88 & 0,88 & 0,88 & 0,88 & 0,78 & 0,55 \\
\hline 10 & $\begin{array}{c}\mathrm{CaAl} \mathrm{Si}_{2} \mathrm{O}_{\text {ganortite }}+2 \cdot \mathrm{H}^{+}+6 \cdot \mathrm{H}_{2} \mathrm{O}= \\
\mathrm{Al}_{2} \mathrm{O}_{3} \cdot 3 \cdot \mathrm{H}_{2} \mathrm{O}_{\text {gibbsite }}+2 \cdot \mathrm{H}_{4} \mathrm{SiO}_{4}{ }^{0}+\mathrm{Ca}^{2+}\end{array}$ & 0,61 & - & 0,55 & 0,64 & 0,64 & 0,64 & 0,64 & 0,64 & 0,58 & - \\
\hline 11 & $\begin{array}{l}\mathrm{CaAl}_{2} \mathrm{Si}_{2} \mathrm{O}_{8} \text { anortite }+2 \cdot \mathrm{H}^{+}+\mathrm{H}_{2} \mathrm{O}= \\
\mathrm{Al}_{2} \mathrm{Si}_{2} \mathrm{O}_{7} \cdot 2 \cdot \mathrm{H}_{2} \mathrm{O}_{\text {kaolinite }}+\mathrm{Ca}^{2+}\end{array}$ & $-0,67$ & 0,51 & $-0,57$ & $-0,63$ & $-0,64$ & $-0,64$ & $-0,64$ & $-0,64$ & $-0,53$ & - \\
\hline
\end{tabular}

Примечание: * коэффициент корреляции г принимается значимым при условии $|r| \geq 2 \cdot \delta_{r}$,; “-” - ниже уровня значимости.

Note: * correlation coefficient $r$ is accepted as significant for condition $|r| \geq 2 \cdot \delta_{r} ; "-"$ is lower than a significance value.

При этом необходимо отметить, что, во-первых, в присуходольной части болота в ряде случаев были установлены концентрации ряда веществ больше, чем в сточных водах на момент опробования, что может объясняться как их накоплением и неполной последующей трансформацией, так и интенсификацией биохимических процессов в болотной экосистеме в результате поступления соединений азота. Во-вторых, концентрации ряда веществ и микроорганизмов в болотных водах на участках поступления стоков с. Мельниково меньше или примерно равны соответствующим показателям фонового участка Обского болота в районе с. Нащеково (табл. 2, 3). В частности, наиболее высокая концентрация ртути $\left(3,256\right.$ мкг/дм $\left.{ }^{3}\right)$ в ноябре 2018 г. отмечена у с. Нащеково, в 100 м от суходола, а уже через 70 м снизилась до 0,025 мкг/дм ${ }^{3}$, что примерно сопоставимо с содержанием на загрязненном участке у с. Мельниково (табл. 3). Наиболее вероятное объяснение этого факта заключается в формировании геохимического барьера при смешении болотных и подземных вод в зоне разгрузки последних на границе болота. Описание соответствующего механизма изложено в [33].

Общим и для нарушенного, и для фонового участков является, прежде всего, наличие значительного количества органических веществ, в составе которых, как и в болотах других районов Западной Сибири [34 38], присутствуют алканы и циклоалканы, ароматические углеводороды с различным числом циклов, а также органические соединения, имеющие в своей структуре кислородсодержащие функциональные группы (спирты, альдегиды, кетоны, карбоновые кислоты, сложные эфиры). Кроме того, в болотных водах обнаружены соединения, содержащие атомы азота - амины и амиды. Среди идентифицированных органических компонентов в загрязненных болотных водах наиболее высокими концентрациями характеризуются сложные эфиры, карбоновые кислоты, спирты, амиды и амины.

Уровень содержания алканов, которые обычно присутствуют в нефтесодержащих стоках, на фоновом участке был несколько выше, чем на нарушенном участке в с. Мельниково (табл. 3). Содержание н-алканов, среди которых идентифицированы как низкомолекулярные гомологи $\mathrm{C}_{16}-\mathrm{C}_{24}$, характерные в основном для бактериальной продукции [39-45], так и высокомолекулярные компоненты н- $\mathrm{C}_{27}$ и н- $\mathrm{C}_{29}$, характерные для многих наземных растений, включая древесные разновидности [41, 46-48], в водах нарушенного участка составляет около $3 \%$. В водах фонового участка (с. Нащёково) содержание налканов, среди которых доминируют низкомолекулярные гомологи (до $\mathrm{C}_{21}$ ), характерные для бактерий, синезеленых водорослей и фитопланктона [47, 49, 50], несколько выше и может достигать $9 \%$. Среди углеводородов н-алканы являются наименее устойчивыми к биохимическому окислению, о чем свидетельствует прямая зависимость их содержания и количества нефтеокисляющих бактерий в водах (табл. 3) [51, 52].

Эфиры и карбоновые кислоты, обнаруженные в болотных водах, являются результатом жизнедеятельности растительности и микроорганизмов. Высокие концентрации данных соединений в воде связаны со сбросом в водные объекты сточных вод предприятий пищевой промышленности, а также хозяйственно-бытовых сточных вод, что является характерным для нарушенного участка. Следует отметить, что сложные эфиры и карбоновые кислоты могут находиться в природных водах не только в коллоидной и растворенной формах, а также могут быть сорбированы взвешенными веществами и донными отложениями. Накопление в водных объектах в повышенных концентрациях карбоновых кислот и сложных эфиров способствует развитию микрофлоры [53]. Содержа- 
ние эфиров, представленных главным образом сложными эфирами бензойной и гексадекановой кислот, в водах нарушенного участка составляет $34 \%$, при приближении к суходолу их содержание увеличивается до $40 \%$. В болотных водах фонового участка содержание эфиров увеличивается с 25 до $41 \%$ по мере приближения к суходолу. Содержание карбоновых кислот, представленных главным образом пальмитиновой и стеариновой кислотами, в водах нарушенного участка составляет около 22-24\%, в водах фонового участка их содержание, по мере удаления от суходола, возрастает с 22 до $30 \%$.

Таблица 2. Макрокомпонентный состав вод Обского болота в 2012 и 2018 гг. (мг/дм³) и расчетные значения индексов насыщения SI

Table 2. Macrocomponent composition of waters of Obskoe bog in 2012 and $2018\left(\mathrm{mg} / \mathrm{dm}^{3}\right)$ and calculated values of the saturation indices $S I$

\begin{tabular}{|c|c|c|c|c|c|c|c|c|c|c|c|c|c|}
\hline \multirow{3}{*}{$\begin{array}{l}\text { Показатель } \\
\text { Indicator }\end{array}$} & \multicolumn{13}{|c|}{ Створ/Discharge point } \\
\hline & \multirow{2}{*}{$\begin{array}{c}\begin{array}{c}\text { Фоновый } \\
\text { участок } \\
\text { Natural } \\
\text { territory }\end{array} \\
\text { III } \\
\end{array}$} & \multicolumn{7}{|c|}{$\begin{array}{l}\text { Антропогенный участок } \\
\text { Anthropogenic territory }\end{array}$} & \multicolumn{3}{|c|}{$\begin{array}{l}\text { Фоновый участок } \\
\text { Natural territory }\end{array}$} & \multicolumn{2}{|c|}{$\begin{array}{c}\text { Антропогенный } \\
\text { участок } \\
\text { Anthropogenic } \\
\text { territory }\end{array}$} \\
\hline & & $\mathrm{I}$ & I & $\mathrm{I}$ & $\mathrm{I}$ & II & II & II & IV & IV & IV & II & II \\
\hline$L, \mathrm{M}$ & 90 & 0 & 110 & 220 & 300 & 120 & 200 & 300 & 100 & 170 & 210 & 200 & 650 \\
\hline $\begin{array}{c}\text { Дата отбора } \\
\text { Sampling date } \\
\end{array}$ & \multicolumn{8}{|c|}{12.11 .12} & \multicolumn{5}{|c|}{26.11 .18} \\
\hline $\mathrm{pH}$ & 7,30 & 7,54 & 7,48 & 7,68 & 7,63 & 7,40 & 7,70 & 7,60 & 7,64 & 7,70 & 7,68 & 7,80 & 7,53 \\
\hline $\begin{array}{c}\Sigma_{\text {ги }} \\
\sum_{\mathrm{mi}} \\
\end{array}$ & 580,8 & 1417,8 & 1425,2 & 1461,8 & 1477,4 & 1486,4 & 1361,4 & 1102,9 & 585,9 & $|543,6|=$ & 527,2 & 1006,0 & 878,9 \\
\hline $\mathrm{Ca}^{2+}$ & 108,2 & 80,0 & 76,0 & 102,0 & 104,0 & 90,1 & 106,4 & 122,8 & 189,9 & \begin{tabular}{|l|}
112,9 \\
\end{tabular} & 125,2 & 99,7 & 113,5 \\
\hline $\mathrm{Mg}^{2+}$ & 21,2 & 26,8 & 26,8 & 25,6 & 24,4 & 26,1 & 29,9 & 32,3 & 14,5 & 19,1 & 20,3 & 26,0 & 25,2 \\
\hline $\mathrm{Na}^{+}$ & 11,1 & 218,0 & 237,0 & 217,7 & 215,7 & 244,8 & 219,6 & 152,6 & 6,7 & 8,1 & 8,3 & 139,5 & 119,5 \\
\hline $\mathrm{K}^{+}$ & 1,6 & 21,1 & 21,1 & 21,1 & 25,8 & 23,6 & 21,0 & 12,8 & 1,6 & 2,4 & 4,1 & 11,8 & 9,2 \\
\hline $\mathrm{HCO}_{3}{ }^{-}$ & 433,1 & 918,7 & 854,0 & 888,2 & 950,4 & 927,2 & 793,0 & 622,2 & 372,0 & \begin{tabular}{|l|l}
398,0 & 3 \\
\end{tabular} & 368,0 & 607,0 & 510,0 \\
\hline $\mathrm{Cl}^{-}$ & 3,5 & 142,0 & 159,8 & 156,2 & 149,1 & 166,9 & 177,5 & 150,9 & 0,4 & 0,5 & 0,2 & 109,6 & 100,3 \\
\hline $\mathrm{SO}_{4}{ }^{2-}$ & 2,1 & 11,2 & 50,5 & 51,0 & 8,0 & 7,7 & 14,0 & 9,3 & 0,1 & 0,1 & 0,1 & 11,9 & 0,1 \\
\hline $\mathrm{NO}_{3}^{-}$ & 1,72 & 0,41 & 0,40 & 0,26 & 0,29 & 0,30 & 0,20 & 3,67 & 0,32 & 0,31 & 0,14 & 0,38 & 0,36 \\
\hline $\mathrm{NO}_{2}^{-}$ & 0,00 & 0,01 & 0,00 & 0,06 & 0,06 & 0,00 & 0,00 & 0,03 & 0,00 & 0,00 & 0,00 & 0,00 & 0,00 \\
\hline $\mathrm{NH}_{4}{ }^{+}$ & 10,00 & 78,13 & 62,40 & 46,80 & 63,18 & 74,00 & 37,00 & 1,05 & 0,07 & 0,14 & 0,07 & 3,06 & 0,30 \\
\hline $\mathrm{Si}$ & 8,17 & 23,45 & 20,97 & 16,69 & 18,79 & 21,54 & 18,59 & 13,33 & 6,29 & 7,10 & 8,85 & 13,02 & 18,62 \\
\hline $\mathrm{Fe}$ & 1,13 & 2,89 & 0,650 & 8,720 & 2,010 & 0,620 & 5,780 & 0,270 & \begin{tabular}{l|l|}
0,530 \\
\end{tabular} & \begin{tabular}{|l|l}
0,770 & 0 \\
\end{tabular} & 0,440 & 2,930 & 2,010 \\
\hline ПО/РО & 1,92 & 31,30 & 34,40 & 17,60 & 16,70 & 12,56 & 8,48 & 4,88 & 1,09 & 5,50 & 8,60 & 5,60 & 8,80 \\
\hline$\Phi K / F A$ & 20,79 & 38,65 & 73,26 & 10,95 & 28,97 & 28,80 & 17,78 & 5,02 & - & - & - & - & - \\
\hline$\Gamma К / \mathrm{HA}$ & 0,34 & 6,99 & 9,37 & 0,34 & 0,02 & 2,19 & 0,54 & 0,17 & - & - & - & - & - \\
\hline $\begin{array}{c}\text { Нефтепродукты } \\
\text { Petroleum products }\end{array}$ & 0,028 & 3,080 & 2,950 & 1,280 & 0,330 & 0,080 & 0,032 & 0,014 & - & - & - & - & - \\
\hline $\begin{array}{c}\text { Номер реакции } \\
\text { (табл. 1) } \\
\text { Number of reaction } \\
\text { (table 1) } \\
\end{array}$ & \multicolumn{13}{|c|}{$\begin{array}{c}\text { Индексы насыщения } S I \\
\text { Saturation indices } S I\end{array}$} \\
\hline 1 & 0,10 & 0,35 & 0,24 & 0,57 & 0,56 & 0,26 & 0,58 & 0,50 & 0,20 & $-0,03$ & 0,12 & 0,19 & $-0,39$ \\
\hline 2 & 0,25 & 0,86 & 0,73 & 0,75 & 0,91 & 0,45 & 0,57 & 0,67 & 2,13 & 2,01 & 1,97 & 2,22 & 2,14 \\
\hline 3 & 0,54 & 1,28 & 1,09 & 1,59 & 1,56 & 1,04 & 1,67 & 1,47 & 0,32 & 0,20 & 0,49 & 0,84 & $-0,38$ \\
\hline 4 & 0,84 & 2,31 & 2,06 & 1,96 & 2,25 & 1,42 & 1,64 & 1,81 & 4,18 & 4,29 & 4,19 & 4,90 & 4,68 \\
\hline 5 & 1,18 & 0,94 & 0,92 & 1,04 & 1,05 & 0,99 & 1,08 & 1,18 & - & - & - & - & - \\
\hline 6 & 0,53 & 0,99 & 0,94 & 0,84 & 0,89 & 0,95 & 0,89 & 0,74 & 0,42 & 0,47 & 0,56 & 0,73 & 0,89 \\
\hline 7 & $-9,67$ & $-4,20$ & $-4,50$ & \begin{tabular}{|l|}
$-5,19$ \\
\end{tabular} & $-4,76$ & $-5,19$ & $-5,34$ & $-6,01$ & $-7,15$ & $-6,68$ & \begin{tabular}{|l|l|}
3 & $-6,36$ \\
\end{tabular} & \begin{tabular}{|l|l|}
6 & $-2,86$ \\
\end{tabular} & $-2,50$ \\
\hline 8 & $-22,07$ & $-16,64$ & $-17,05$ & $-17,26$ & $-16,87$ & $-17,04$ & $-16,94$ & $-18,42$ & $-22,10$ & $-21,30$ & \begin{tabular}{|l|l|}
0 & $-20,30$ \\
\end{tabular} & \begin{tabular}{|l|l|}
0 & $-18,17$ \\
\end{tabular} & $-17,97$ \\
\hline 9 & $-0,84$ & 1,83 & 1,71 & 2,11 & 2,19 & 1,65 & 2,15 & 1,53 & $-0,18$ & 0,31 & 0,73 & 1,87 & 1,12 \\
\hline 10 & $-4,76$ & $-3,61$ & $-3,84$ & \begin{tabular}{|l|}
$-3,52$ \\
\end{tabular} & $-3,51$ & $-3,91$ & $-3,36$ & $-3,74$ & $-4,07$ & $-4,06$ & \begin{tabular}{|l|l|}
5 & $-3,87$ \\
\end{tabular} & \begin{tabular}{|l|l|}
7 & $-3,45$ \\
\end{tabular} & $-3,61$ \\
\hline 11 & $-21,82$ & $-20,11$ & $-20,50$ & $-20,68$ & $-20,21$ & $-21,89$ & $-21,30$ & $-20,69$ & $-14,48$ & \begin{tabular}{|l|l|} 
& $-14,72$ \\
\end{tabular} & \begin{tabular}{|l|l|}
2 & $-14,80$ \\
\end{tabular} & \begin{tabular}{|l|l|}
0 & $-14,30$ \\
\end{tabular} & $-14,46$ \\
\hline
\end{tabular}

Примечание: I - створ выпуска сточных вод с. Мельниково; II - створ вдоль дороги с. Мельниково - с. Старая Шегарка (ниже по уклону рельефа от выпуска I); III - створ в черте с. Нащеково; IV - створ в 4 км южнее с. Нашеково; $L$ - расстояние от суходола, $м$; $\Sigma_{z и}$ - сумма главных ионов; ПО - перманганатная окисляемость; ФК и ГК - фульвои гуминовые кислоты; SI-индекс насыщения по реакииям, номера которых приведены в табл. 1 .

Note: I - wastewater discharge point in Melnikovo; II - discharge point along the Melnikovo road - village Staraya Shegarka (lower by relief slope from discharge point I); III - discharge point in Nashchekovo; IV - discharge point, $4 \mathrm{~km}$ to the south of Nashchekovo; $L$-distance from dry valley, $m ; \Sigma_{m i}$ - sum of the main ions; PO-permanganate oxidability; FA and HA - fulvic and humic acids; SI - saturation index by reactions, numbers of which are given in table 1. 
Известия Томского политехнического университета. Инжиниринг георесурсов. 2020. Т. 331. № 3. 39-51

Иванова И.С. и др. Условия трансформации коммунально-бытовых сточных вод в болотных экосистемах (на примере Обского ...

Таблица 3. Химический состав вод Обского болота (дата отбора проб 26.11.2018 г.).

Table 3. Chemical composition of the waters of Obskoe bog (date of sampling 26.11.2018).

\begin{tabular}{|c|c|c|c|c|c|c|}
\hline \multirow{2}{*}{$\begin{array}{l}\text { Показатель } \\
\text { Indicator }\end{array}$} & \multirow{2}{*}{$\begin{array}{c}\text { Единицы измерения } \\
\text { Units of measure }\end{array}$} & \multicolumn{5}{|c|}{ Створ/Discharge point } \\
\hline & & IV & IV & IV & II & II \\
\hline$L$ & $\mathrm{M} / \mathrm{m}$ & 100 & 170 & 210 & 200 & 650 \\
\hline Широта/Latitude & $\circ$ & 56,515 & 56,515 & 56,514 & 56,552 & 56,551 \\
\hline Долгота/Longitude & $\circ$ & 84,026 & 84,027 & 84,027 & 84,103 & 84,110 \\
\hline Температура воды/Water temperature & ${ }^{\circ} \mathrm{C}$ & 0,3 & 0,5 & 0,3 & 0,5 & 0,1 \\
\hline $\mathrm{pH}$ & единицы $\mathrm{pH} /$ measure $\mathrm{pH}$ & 7,64 & 7,70 & 7,68 & 7,80 & 7,53 \\
\hline УЭП/Conductivity & мкC/см/ $/ \mu \mathrm{S} / \mathrm{cm}$ & 442 & 462 & 456 & 1036 & 893 \\
\hline$N_{\text {неopr } r} N_{\text {inorganic }}$ & \multirow{3}{*}{$\begin{array}{c}\mathrm{M \Gamma} / \mathrm{дM}^{3} \\
\mathrm{mg} / \mathrm{dm}^{3}\end{array}$} & 0,125 & 0,179 & 0,089 & 2,462 & 0,315 \\
\hline Фосфаты/Phosphates & & 0,076 & 0,060 & 0,170 & 0,150 & 0,140 \\
\hline $\mathrm{F}^{-}$ & & 0,36 & 0,38 & 0,32 & 0,20 & 0,22 \\
\hline \multicolumn{7}{|c|}{ Микроэлементный состав/Trace elements } \\
\hline $\mathrm{Li}$ & \multirow{29}{*}{$\begin{array}{l}\text { мкг/дм }{ }^{3} \\
\mu \mathrm{g} / \mathrm{dm}^{3}\end{array}$} & 3,94 & 5,24 & 4,84 & 6,40 & 5,47 \\
\hline B & & 54,7 & 50,6 & 64,5 & 59,5 & 74,3 \\
\hline $\mathrm{Al}$ & & 170,6 & 36,1 & 63,2 & 2,1 & 83,2 \\
\hline $\mathrm{Sc}$ & & 0,90 & 0,83 & 1,08 & 1,16 & 2,11 \\
\hline $\mathrm{Ti}$ & & 8,63 & 2,22 & 4,83 & 4,73 & 20,23 \\
\hline $\mathrm{V}$ & & 0,68 & 0,25 & 0,39 & 0,14 & 1,27 \\
\hline $\mathrm{Cr}$ & & 3,73 & 2,93 & 3,35 & 4,35 & 4,35 \\
\hline $\mathrm{Mn}$ & & 1511,3 & 474,2 & 784,9 & 307,0 & 988,1 \\
\hline Co & & 1,28 & 0,28 & 0,48 & 0,44 & 1,55 \\
\hline $\mathrm{Ni}$ & & 1,74 & 0,40 & 0,36 & 3,83 & 5,83 \\
\hline $\mathrm{Cu}$ & & 1,19 & 0,48 & 0,75 & 0,23 & 1,10 \\
\hline $\mathrm{Zn}$ & & 17,36 & 8,77 & 12,61 & 1,00 & 9,79 \\
\hline $\mathrm{Ga}$ & & 0,11 & 0,03 & 0,06 & 0,01 & 0,09 \\
\hline Ge & & 0,03 & 0,01 & 0,02 & 0,01 & 0,07 \\
\hline As & & 40,52 & 5,41 & 21,42 & 22,21 & 242,77 \\
\hline $\mathrm{Se}$ & & 0,10 & 0,16 & 0,22 & 0,58 & 0,66 \\
\hline $\mathrm{Br}$ & & 12,21 & 7,61 & 5,60 & 207,38 & 196,14 \\
\hline $\mathrm{Rb}$ & & 1,02 & 0,73 & 1,57 & 6,10 & 3,27 \\
\hline $\mathrm{Sr}$ & & 880,0 & 638,9 & 715,5 & 756,0 & 977,8 \\
\hline $\mathrm{Y}$ & & 0,356 & 0,076 & 0,123 & 0,018 & 0,460 \\
\hline $\mathrm{Zr}$ & & 0,081 & 0,029 & 0,039 & 0,024 & 0,236 \\
\hline $\mathrm{Nb}$ & & 0,004 & 0,000 & 0,000 & 0,004 & 0,014 \\
\hline Mo & & \begin{tabular}{|l|}
0,432 \\
\end{tabular} & 0,114 & 0,018 & 0,015 & 0,074 \\
\hline $\mathrm{Ru}$ & & 0,003 & 0,001 & 0,004 & 0,001 & 0,007 \\
\hline $\mathrm{Rh}$ & & 0,020 & 0,014 & 0,018 & 0,018 & 0,021 \\
\hline $\mathrm{Ag}$ & & 0,003 & 0,003 & 0,000 & 0,002 & 0,004 \\
\hline $\mathrm{Cd}$ & & 0,100 & 0,045 & 0,043 & 0,005 & 0,039 \\
\hline Sn & & 0,027 & 0,025 & 0,008 & 0,018 & 0,126 \\
\hline $\mathrm{Sb}$ & & 0,034 & 0,024 & 0,023 & 0,045 & 0,054 \\
\hline $\mathrm{Te}$ & \multirow{21}{*}{ мкг $/$ дм $^{3} \mu \mathrm{g} / \mathrm{dm}^{3}$} & 0,011 & 0,013 & 0,006 & 0,006 & 0,014 \\
\hline $\mathrm{I}$ & & 10,0 & 3,4 & 6,8 & 16,1 & 31,5 \\
\hline Cs & & 0,008 & 0,003 & 0,015 & 0,005 & 0,007 \\
\hline $\mathrm{Ba}$ & & 168,9 & 84,8 & 217,9 & \begin{tabular}{|l|}
136,9 \\
\end{tabular} & \begin{tabular}{|l|l}
484,4 \\
\end{tabular} \\
\hline $\mathrm{Lu}$ & & 0,004 & 0,001 & 0,002 & $<0,001$ & 0,004 \\
\hline $\mathrm{Hf}$ & & 0,005 & $<0,001$ & 0,002 & \begin{tabular}{|l|}
0,003 \\
\end{tabular} & 0,008 \\
\hline $\mathrm{Ta}$ & & 0,013 & \begin{tabular}{|l|}
0,007 \\
\end{tabular} & 0,005 & 0,024 & \begin{tabular}{|l|}
0,007 \\
\end{tabular} \\
\hline $\mathrm{W}$ & & 0,009 & 0,003 & 0,005 & 0,006 & 0,014 \\
\hline $\mathrm{Au}$ & & \begin{tabular}{|l|}
0,003 \\
\end{tabular} & $<0,001$ & 0,003 & 0,003 & 0,003 \\
\hline $\mathrm{Hg}$ & & 3,256 & $<0,050$ & $<0,050$ & 0,038 & $<0,050$ \\
\hline $\mathrm{Pb}$ & & 2,869 & 1,338 & 1,792 & \begin{tabular}{|l|}
0,064 \\
\end{tabular} & 2,357 \\
\hline $\mathrm{La}$ & & 0,396 & \begin{tabular}{|l|}
0,084 \\
\end{tabular} & 0,123 & 0,011 & 0,332 \\
\hline $\mathrm{Ce}$ & & \begin{tabular}{|l|}
0,795 \\
\end{tabular} & \begin{tabular}{|l|}
0,159 \\
\end{tabular} & 0,253 & 0,018 & 0,716 \\
\hline $\operatorname{Pr}$ & & 0,099 & 0,020 & 0,031 & 0,002 & 0,081 \\
\hline $\mathrm{Nd}$ & & 0,382 & 0,071 & 0,117 & 0,006 & 0,346 \\
\hline $\mathrm{Sm}$ & & \begin{tabular}{|l|}
0,093 \\
\end{tabular} & 0,018 & 0,029 & 0,004 & 0,078 \\
\hline $\mathrm{Eu}$ & & 0,065 & 0,028 & 0,070 & 0,035 & 0,138 \\
\hline $\mathrm{Gd}$ & & 0,089 & 0,017 & 0,029 & 0,012 & 0,091 \\
\hline $\mathrm{Yb}$ & & 0,022 & 0,003 & 0,007 & 0,001 & 0,028 \\
\hline Th & & \begin{tabular}{|l|}
0,029 \\
\end{tabular} & \begin{tabular}{|l|}
0,013 \\
\end{tabular} & 0,007 & 0,004 & 0,036 \\
\hline $\mathrm{U}$ & & 0,029 & 0,059 & 0,017 & 0,004 & 0,042 \\
\hline БO/COD & $\mathrm{MrO}_{2} / \mathrm{дM}^{3} / \mathrm{mgO}_{2} / \mathrm{dm}^{3}$ & 10,00 & 11,40 & 5,80 & 23,30 & 24,60 \\
\hline \multicolumn{7}{|c|}{ Органические соединения/Organic compounds } \\
\hline Алканы/Alkanes & \multirow{4}{*}{ 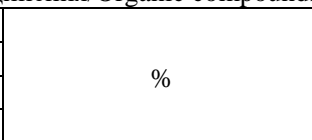 } & 8,45 & 9,51 & 4,44 & 2,60 & 2,65 \\
\hline Циклоалканы/Cycloalkanes & & 2,28 & 0,24 & 1,48 & 0,00 & 0,52 \\
\hline Ароматические углеводороды/Aromatic hydrocarbons & & 0,61 & 1,20 & 4,11 & 0,00 & 0,00 \\
\hline Спирты/Alcohols & & 9,43 & 18,28 & 16,37 & 14,61 & 10,55 \\
\hline
\end{tabular}




\section{Окончание табл. 3}

\section{Table 3}

\begin{tabular}{|c|c|c|c|c|c|c|}
\hline \multirow{2}{*}{$\begin{array}{l}\text { Показатель } \\
\text { Indicator }\end{array}$} & \multirow{2}{*}{$\begin{array}{c}\text { Единицы измерения } \\
\text { Units of measure }\end{array}$} & \multicolumn{5}{|c|}{ Створ/Discharge point } \\
\hline & & IV & IV & IV & II & II \\
\hline Альдегиды/Aldehydes & & 0,13 & 2,98 & 0,09 & 0,00 & 0,36 \\
\hline Кетоны/Ketones & & 3,34 & 5,92 & 3,59 & 2,91 & 0,55 \\
\hline Карбоновые кислоты/Carboxylic acids & & 21,62 & 29,57 & 30,14 & 24,39 & 22,46 \\
\hline Эфиры/Esters & & 41,70 & 32,30 & 25,07 & 40,36 & 34,42 \\
\hline Амиды/Amides & & 0,54 & 0,00 & 14,72 & 14,67 & 14,56 \\
\hline Амины/Amines & & 11,91 & 0,00 & 0,00 & 0,47 & 13,93 \\
\hline \multicolumn{7}{|c|}{ Микробиологический состав/Microbiological composition } \\
\hline олиготрофнные/oligotrophic & \multirow{11}{*}{$\begin{array}{c}\text { кл/мЛ } \\
\text { cell/mL }\end{array}$} & 9800 & 11620 & 13750 & 12350 & 3880 \\
\hline олигонитрофилы/oligonitrophilic & & 3600 & 2320 & 2200 & 4150 & 5190 \\
\hline нефтеокисляющие/oil-oxidizing & & 5640 & 8200 & 2470 & 830 & 1160 \\
\hline азотфиксирующие/nitrogen-fixing & & 4600 & 2200 & 2400 & 1260 & 1800 \\
\hline уробактерии/urobacteria & & 3520 & 9280 & 2000 & 2400 & 1260 \\
\hline аммонифицурующие/ammonifying & & 102 & 102 & 101 & 103 & 102 \\
\hline тионовые/thionobacteria & & 20120 & 8650 & 22850 & 14720 & 4230 \\
\hline сульфатвосстанавливающие/sulphate reducing & & 10000 & 1000 & 0 & 10000 & 1000 \\
\hline железобактерии гетеротрофные/heterotrophic iron-oxidizing & & 2540 & 2400 & 37600 & 840 & 4700 \\
\hline образующие гидроксиды железа/hydroxide-forming & & 2500 & 2090 & 1300 & 120 & 0 \\
\hline окисляющие соединения Mn/manganese-oxidizing & & 460 & 50 & 0 & 0 & 0 \\
\hline
\end{tabular}

Примечание: номера створов соответствуют табл. 2; L-расстояние от суходола; УЭП - удельная электропроводность; $\mathrm{N}_{\text {неор. }}-$ азот $\mathrm{NO}_{3}^{-}, \mathrm{NO}_{2}^{-}$и $\mathrm{NH}_{4}^{+}$; БО -бихроматная окисляемость.

Note: the numbers of discharge point correspond to table 2; L - distance from dry valley, m; Conductivity - electrical conductivity; $\mathrm{N}_{\text {inorganic }}$ - nitrogen $\mathrm{NO}_{3}{ }^{-}, \mathrm{NO}_{2}{ }^{-}$and $\mathrm{NH}_{4}{ }^{+}$; $\mathrm{COD}$ - chemical oxygen demand.
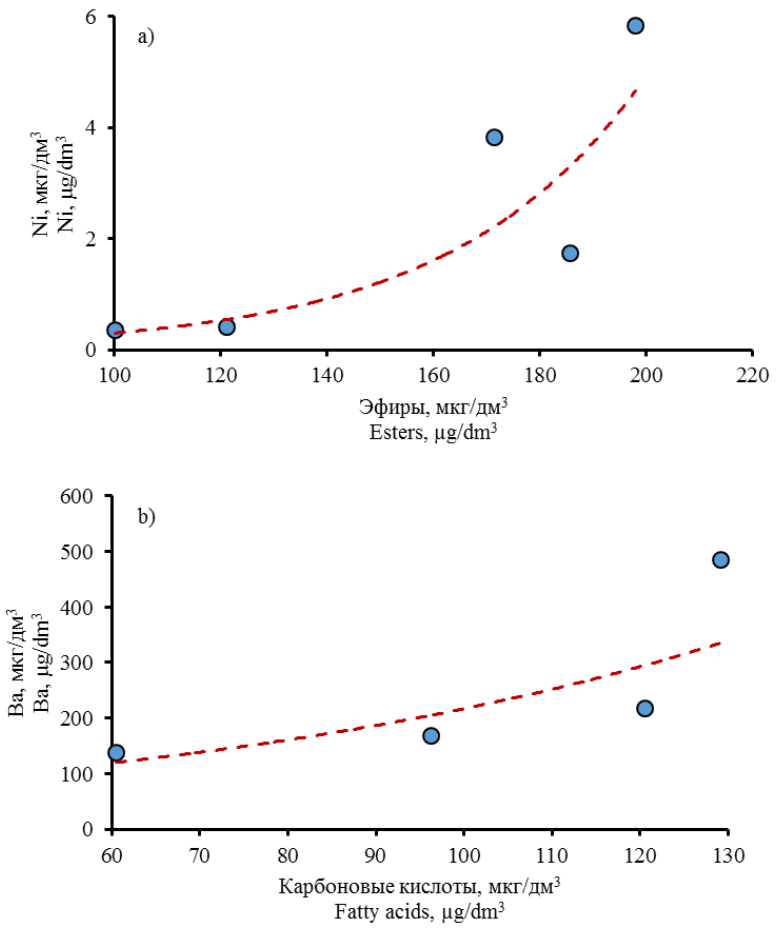

Pис. 2. Соотночение концентращий Ni и эфиров (a), Ba и карбоновых кислот (b) в водах Обского болота в ноябре 2018 г.

Fig. 2. Ratio of concentrations of Ni and ethers (a), Ba and fatty acids (b) in waters of the Obskoe bog in November 2018

Вопрос взаимосвязи содержания микроэлементов и растворенного органического вещества, представляющего сложную смесь соединений ациклического и циклического строения, остается до сих пор мало изученным. Для установления роли отдельных групп органических соединений в процессах миграции и накопления микроэлементов в водах проведена оценка зависимости содержаний кислородорганических соединений и некоторых микроэлементов в исследуемых объектах (рис. 2, $a$, б). Полученные результаты свидетельствуют об устойчивой тенденции к возрастанию концентраций Ni и Ва с увеличением содержаний сложных эфиров и карбоновых кислот соответственно в болотных водах как нарушенного, так и фонового участков. Таким образом, приведенные данные позволяют предположить, что кислородсодержащие органические соединения способствуют накоплению микроэлементов в водах независимо от степени антропогенного воздействия на них.

Для болотных вод с разной степенью антропогенного воздействия характерны примерно одинаковые содержания олиготрофных, аммонифицирующих, тионовых и сульфатвосстанавливающих бактерий (табл. 3), причем концентрации олиготрофных и аммонифицирующих микроорганизмов в болотных водах были во всех случаях существенно ниже, чем в среднем в речных водах в бассейне Средней Оби, а концентрации бактерий цикла серы - многократно меньше. Заметное увеличение в водах нарушенного участка отмечено только для олигонитрофилов - бактерий, приспособленных к среде с весьма низким содержанием легкоусвояемых органических веществ, но с относительно повышенным содержанием соединений азота.

Еще одной общей закономерностью является ненасыщенность болотных вод относительно первичных алюмосиликатов, пересыщение относительно карбонатов, гуматов кальция и кварца и колебания величины SI для реакций трансформаций слюды в глинистые минералы от недонасыщенности относительно микроклина на фоновом участке до пересыщения при максимальном приближении к выпуску 
сточных вод (табл. 2). Значения индексов насыщения относительно некоторых минералов изменяются пропорционально изменениям содержаний микрофлоры, причем эта связь в ряде случаев нелинейная. Например, насыщение относительно кальцита в отсутствие растворенного углекислого газа возрастает от $-0,39$ до 0,20 при увеличении концентраций тионовых бактерий примерно до 20 тыс. кл/мл, а потом при дальнейшем увеличении последних снижается до 0,12 (рис. 3). Статистически значимая связь степени насыщения болотных вод наблюдается и с содержаниями главных ионов (табл. 1), причем сумма главных ионов в болотных водах удовлетворительно определяется влиянием реакций растворения - осаждения карбонатных минералов и кварца, широко представленных в составе минеральных включений в торфа низинных болот Томской области [54]:

$$
\begin{gathered}
\Sigma_{\text {ги }}=(277,15 \pm 60,01) \cdot S I(3)+ \\
\quad+(1093,67 \pm 83,44) \cdot S I(6),
\end{gathered}
$$

где $\operatorname{SI}(3)$ и $\operatorname{SI}(6)$ - индексы насыщения, соответствующие номерам реакций в табл. 1; квадрат корреляционного отношения $R^{2}=0,93$.

Дополнительно к изучению изменений химического состава болотных вод деятельного горизонта торфяной залежи по мере удаления от суходола и выпуска сточных вод (также на границе болота и суходола) было выполнено определение состава водных и кислотных вытяжек из торфов до глубины 3 м от поверхности болота в пункте, расположенном в 200 м от суходола в створе II (табл. 3). В результате был подтвержден полученный ранее [33] вывод о наличии геохимического барьера примерно на границе деятельного и инертного горизонтов (рис. 4). Миграция загрязняющих веществ ниже 1 м от поверхности болота, безусловно, возможна, но ее масштаб несопоставим с переносом в деятельном горизонте по линиям стока.

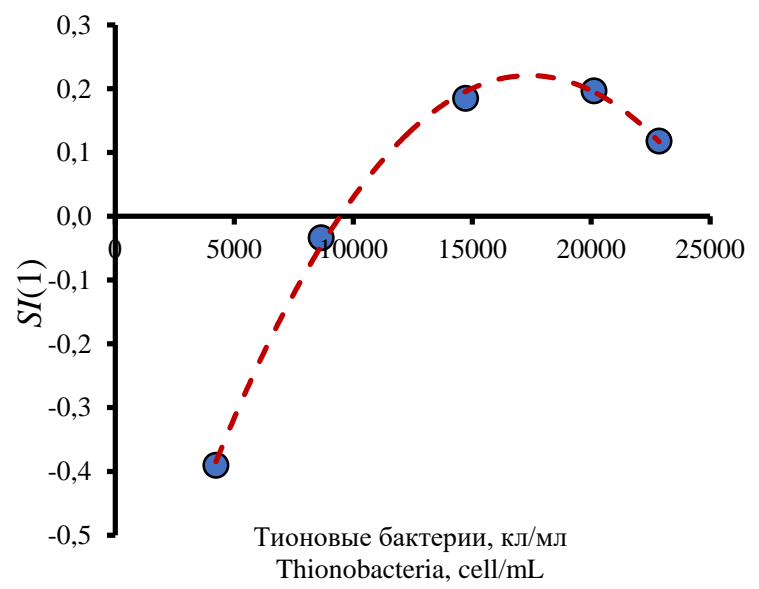

Pис. 3. Соотношение индексов насыщения относительно кальц̧ита (реакциия 1 в табл. 1) и содержаний тионовых бактерий в водах Обского болота в ноябре 2018 г.

Fig. 3. Ratio of saturation indices relative to calcite (reaction 1 in Table 1) and contents of thionobacteria in waters of the Obskoe bog in November 2018

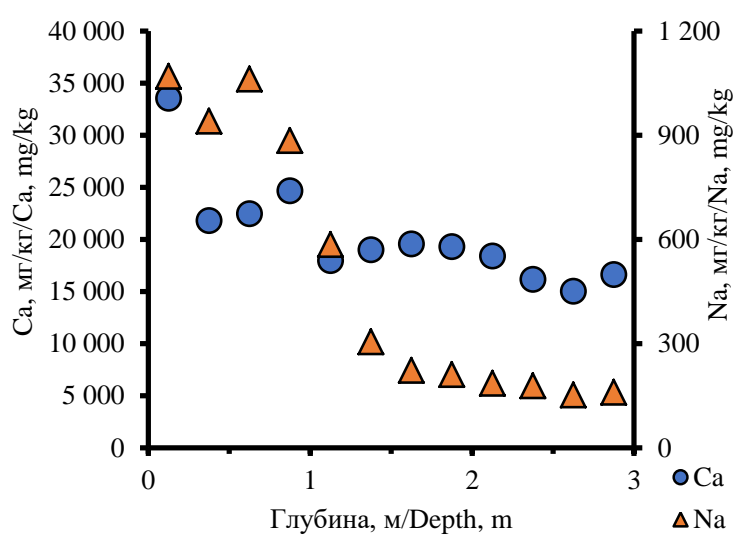

Рис. 4. Изменение по глубине торфяной залежи Обского болота концентраций Сa и Na в кислотных вытяжках из торфов (пункт в 200 м от суходола в створе II, табл. 2) в ноябре 2018 г.

Fig. 4. Change of $\mathrm{Ca}$ and Na concentrations in depth of the peat deposit of the Obskoe bog in acid extracts from peats (point $200 \mathrm{~m}$ from dry valley in discharge point II, table 2) in November 2018

\section{Заключение}

В результате проведенных исследований установлено:

1) в водах низинного болота, независимо от степени антропогенного воздействия, наблюдается превышение нормативов качества хозяйственно-питьевого и рыбохозяйственного водопользования по содержанию органических веществ (по бихроматной и перманганатной окисляемости, концентрациям конкретных органических веществ), продуктов их трансформации (включая $\mathrm{NH}_{4}^{+}$, амины и производные карбоновых кислот) и соединений с металлами (например, комплексы органических кислот и $\mathrm{Fe}$ );

2) антропогенное влияние на состояние Обского болота наиболее ощутимо сказывается в увеличении растворенных органических соединений в водах, представленных главным образом сложными эфирами и карбоновыми кислотами, которые способствуют развитию микроорганизмов, а также приводит к определенному концентрированию ряда химических элементов в болотных водах нарушенных участков болота в виде комплексных соединений со сложными эфирами и карбоновыми кислотами;

3) накопление веществ, поступающих с коммунально-бытовыми сточными водами с. Мельниково, происходит в основном на геохимическом барьере на границе деятельного и инертного горизонтов торфяной залежи и чуть несколько ниже (примерно до глубины около 1 м), что, впрочем, не исключает поступление загрязняющих веществ в нижерасположенные слои, но уже в заметно меньшем количестве;

4) с учетом полученных данных, во-первых, нет оснований отрицать допустимость и экологическую оправданность ограниченного сброса коммунально-бытовых сточных вод в болото, поскольку это не приводит к существенному изменению хими- 
ческого состава болотных вод, а антропогенное воздействие лимитируется микробиологическими и геохимическими условиями в болоте; во-вторых, стратегия охраны низинного Обского болота на участке сброса сточных вод с. Мельниково должна включать мероприятия химической мелиорации (например, известкование);

5) с учетом масштабов заболоченности таежной зоны Западной Сибири целесообразно пересмотреть и/или скорректировать природоохранные мероприятия по некоторому ограничению роста забо-

\section{СПИСОК ЛИТЕРАТУРЫ}

1. Торфяные ресурсы мира / В.Д. Марков, А.С. Оленин, Л.А. Оспенникова, Е.И. Скобеева, П.И. Хорошев / под ред. А.С. Оленина. - М.: Недра, 1988. -383 с.

2. Status of wetlands in China: a review of extent, degradation, issues and recommendations for improvement / W. Meng, M. He, B. Hu, X. Mo, H. Li, B. Liu, Zh. Wang // Ocean \& Coastal Management. 2017. - V. 146. - P. 50-59. URL: http://dx.doi.org/10.1016/ j.ocecoaman.2017.06.003 (дата обращения 01.10.2019).

3. Marsh wetland degradation risk assessment and change analysis: a case study in the Zoige Plateau, China / W. Jianga, J. Lv, C. Wang, Zh. Chen, Y. Liu // Ecological Indicators. - 2017. - V. 82. P. 316-326. URL: http://dx.doi.org/10.1016/j.ecolind.2017.06.059 (дата обращения 01.10.2019).

4. Global wetlands: potential distribution, wetland loss, and status / S. Hu, Zh. Niu, Y. Chen, L. Li, H. Zhang // Science of the Total Environment. 2017. - V. 586. - P. 319-327. DOI: 10.1016/j.scitotenv. 2017.02.001.

5. Нейштадт М.И. Болота Обь-Иртышского междуречья // Природные условия освоения междуречья Обь-Иртыш / отв. ред. М.И. Нейштадт, Г.Д. Рихтер. - М.: АН СССР, Институт географии, 1972. - С. 322-346.

6. Болотные системы Западной Сибири и их природоохранное значение / О.Л. Лисс, Л.И. Абрамова, Н.А. Аветов, Н.А. Березина, Л.И. Инишева, Т.В. Курнишкова, З.А. Слука, Т.Ю. Толпышева, Н.К. Шведчикова / под ред. В.Б. Куваева. - Тула: Гриф и К ${ }^{\circ}, 2001 .-584$ с.

7. Пологова Н.Н., Лапшина Е.Д. Накопление углерода в торфяных залежах Большого Васюганского болота // Большое Васюганское болото. Современное состояние и процессы развития / под ред. М.В. Кабанова. - Томск: Изд-во ИОА СО РАН, 2002. - C. 174-179.

8. Eurasian mires of the Southern Taiga Belt: modern features and response to Holocene palaeoclimate / T. Minayeva, W. Bleuten, A. Sirin, E.D. Lapshina // Wetlands and Natural Resource Management. Ecological Studies. V. 190 / Eds. J.T.A. Verhoeven, B. Beltman, R. Bobbink, D.F. Whigham. - Berlin; Heidelberg: Springer-Verlag, 2006. - P. 315-341.

9. Состав и особенности изменения со временем водорастворимого комплекса органических веществ нефтезагрязненной водной среды / М.Г. Кульков, Ю.В. Коржов, В.Ю. Артамонов, В.В. Углев // Известия Томского политехнического университета. - 2012. - Т. 320. - № 1. - С. 193-199.

10. Экологическое состояние водных объектов на территории нефтедобывающих комплексов Среднего Приобья / Л.К. Алтунина, Л.И. Сваровская, И.Г. Ященко, Е.А. Ельчанинова // Нефтехимия. - 2017. - Т. 57. - № 3. - С. 340-345. DOI: $10.7868 / \mathrm{S} 0028242117020034$

11. Tong Yi., Mayera B.K., McNamara P.J. Adsorption of organic micropollutants to biosolids-derived biochar: estimation of thermodynamic parameters // Environmental Science: Water Research \& Technology. - 2019. - Iss. 6. - P. 1132-1144. DOI: 10.1039/C8EW00854J.

12. Охрана окружающей среды в территориальном ЗападноСибирском комплексе / В.А. Шишов, В.Ю. Шеметов, В.И. Рябченко, В.П. Парфенов. - М.: ВНИИОЭНГ, 1988. - 50 с.

13. Inisheva L.I., Kobak K.I., Inishev N.G. Paludification on Vasyugan mire contemporary // Problems of Ecology. - 2017. - V. 10. - № 2. - P. 105-110. DOI: 10.1134/S1995425517020044. лоченности региона за счет увеличения лесных угодий вследствие осушительных мелиораций и дополнительного внесения соединений азота и кальция, в том числе, входящих в состав сточных вод жилищно-коммунального хозяйства и нефтегазодобывающего комплекса.

Работа выполнена при финансовой поддержке грантов РФФИ № 18-55-80015, 17-05-00042, 19-05-00290. Изучение формирования геохимического барьера на участке Обского болота выполнено за счет средств гранта РНФ № 19-77-00014.

14. Ecosystem recovery and natural degradation of spilled crude oil in peat bog ecosystems of West Siberia / W. Bleuten, E. Lapshina, W. Ivens, V. Shinkarenko, E. Wiersma // International Peat Journal. - 1999. - № 9. - P. 73-82.

15. Методика разработки нормативов допустимых сбросов веществ и микроорганизмов в водные объекты для водопользователей (с изменениями от 31.07.2018 г.). Утв. Приказом Мин. природных ресурсов России от 17.12.2007 г. № 333. - М.: МПР России, 2018. -35 с

16. ГОСТ 21123-85. Торф. Термины и определения. Дата введения 01.07.1986 г. - М.: Изд-во стандартов, 1985. - 85 с.

17. Химический состав вод Обского болота (Западная Сибирь) и его пространственные изменения под влиянием сбросов загрязняющих веществ / О.Г. Савичев, Н.В. Гусева, Е.А. Куприянов, А.А. Скороходова, К.В. Ахмед-Оглы // Известия Томского политехнического университета. - 2013 - Т. 323. № 1. - C. 168-172.

18. Торфяные месторождения Томской области / под ред. Я.Н. Задуницкого, И.И. Казакова, В.Д. Маркова. - М.: Геолторфразведка, 1971. - 306 с.

19. Vegetation characteristics and eco-hydrological processes in a pristine mire in the Ob River valley (Western Siberia) / A.M. Schipper, R. Zeefat, F. Tanneberger, J.P. van Zuidam, W. Hahne, S.A. Schep, S. Loos, W. Bleuten, H. Joosten, E.D. Lapshina, M.J. Wassen // Plant Ecology. - 2007. - V. 193. P. 131-145. DOI: 10.1007/s11258-006-9253-x.

20. Изменения химического состава кислотных вытяжек по глубине торфяной залежи внутриболотных экосистем Васюганского болота (Западная Сибирь) / О.Г. Савичев, А.К. Мазуров, М.А. Рудмин, А.А. Хващевская, А.Б. Даулетова // Известия Томского политехнического университета. Инжиниринг георесурсов. - 2018. - Т. 329. - № 9. - С. 101-116.

21. Mezhibor A.M., Arbuzov S.I., Arkhipov V.S. Trace elements in peat bogs of Tomsk region (South Siberia, Russia) // Energy exploration \& exploitation. - 2013. - V. 31. - № 4. - P. 629-644.

22. Modes of occurrence of rare earth elements in peat from Western Siberia / S.I. Arbuzov, S.G. Maslov, R.B. Finkelman, A.M. Mezhibor, S.S. Ilenok, M.G. Blokhin, E.V. Peregudina // Journal of Geochemical Exploration. - 2018. - V. 184. - P. 40-48.

23. Экология микроорганизмов /под ред. А.И Нетрусова. - М.: AKADEMA, 2004. - $267 \mathrm{c}$.

24. Сапротрофный бактериальный комплекс верховых торфяников Западной Сибири / А.В. Головченко, Ю.В. Санникова, Т.Г. Добровольская, Д.Г. Звягинцев // Микробиология. 2005. - Т. 74. - № 4. - С. 545-551.

25. МУК 4.1. 663-97. Методические указания Определение массовой концентрации органических соединений в воде методом хромато-масс-спектрометрии. - М.: Министерство здравоохранения России, 1997. -4 c.

26. Soniassy R., Sandra P., Schlett C. Water analysis: organic micropollutants. - Germany: Hewlett-Packard Company, 1994. $278 \mathrm{p}$.

27. The choice of sorbent for adsorption extraction of chloroform from drinking water / T.A. Krasnova, I.V. Timoshchuk, A.K. Gorelkina, J. Dugarjav // Foods and Raw Materials. - 2017. - V. 5. - № 2. P. 189-196. DOI: 10.21179/2308-4057-2017-2-189-196.

28. Schmidt T.C. Recent trends in water analysis triggering future monitoring of organic micropollutants // Analytical and Bioanalytical Chemistry. 2018. - V. 410. - Iss. 17. - P. 3933-3941. URL: https://doi.org/ 10.1007/s00216-018-1015-9 (дата обращения 01.10.2019). 
29. Орлов Д.С. Химия почв. - М.: Изд-во Московского университета, 1985. - $376 \mathrm{c}$.

30. Wilkinson G.M., Pace M.L., Cole J.J. Terrestrial dominance of organic matter in north temperate lakes // Global Biogeochemical Cycles. -2013 . - V. 27. - P. 1-9.

31. Hydrophilic interaction liquid chromatography coupled to mass spectrometry-based detection to determine emerging organic contaminants in environmental samples / D. Salas, F. Borrull, N. Fontanals, R.M. Marcé // Trends in analytical chemistry. 2017. - V. 94. - P. 141-149. URL: https://doi.org/10.1016/ j.trac.2017.07.017 (дата обращения 01.10.2019).

32. Пособие по определению расчетных гидрологических характеристик / под ред. А.В. Рождественского, А.Г. Лобановой. Л.: Гидрометеоиздат, 1984. - 448 с.

33. Механизмы концентрирования химических элементов в торфяной залежи в восточной части Васюганского болота (Западная Сибирь) / О.Г. Савичев, А.К. Мазуров, М.А. Рудмин, Н.Е. Шахова, В.И. Сергиенко, И.П. Семилетов // Doklady earth sciences. - 2019. - V. 486. - № 3. - C. 350-350. DOI: https://doi.org/10.31857/S0869-56524863350-353.

34. Органические примеси в природных водах в районе г. Стрежевого / Ю.П. Туров, И.Д. Пирогова, М.Ю. Гузняева, Н.А. Ермашова // Водные ресурсы. - 1998. - Т. 25. - № 4. C. $455-461$.

35. Organic trace contaminants in fresh natural waters from the drainage basins of Tom' and Upper Ob' rivers / A.E. Kontorovich, S.L. Shvartsev, V.A. Zuev, N.M. Rasskazov, Y.P. Turov // Geochemistry International. - 2000. - V. 38. - № 5. - P. 480-490.

36. Gorbov S.N., Bezuglova O.S. Specific features of organic matter in urban soils of Rostov-on-Don // Eurasian Soil Science. 2014. - V. 47. - № 8. - P. 792-800.

37. Формирование состава органических веществ в малых озерах Западной Сибири / Л.П. Паничева, Т.И. Моисеенко, Т.А. Коемлева, С.С. Волкова // Вестник Тюменского государственного университета. Экология и природопользование. - 2015. T. 1. - № 1. - C. 151-163.

38. Efremova T.T., Efremov S.P., Kalacheva G.S. Organic trace components extractable by chloroform from swamp and river waters in the middle $\mathrm{Ob}$ basin // Water resources. - 2018. V. 45. - № 5. - P. 757-766. DOI: 10.1134/S0097807818050068.

39. Сезонная динамика распределения органических соединений в болотных водах южной тайги (Западная Сибирь) / О.В. Серебренникова, Е.Б. Стрельникова, И.В. Русских, Ю.А. Харанжевская, Е.С. Воистинова // Химия в интересах устойчивого развития. - 2019. - № 27. - С. 65-72.

40. Тиссо Б., Вельте Д. Образование и распространение нефти и газа. - М.: Мир, 1981. - 501c.

41. An n-alkane proxy for the sedimentary input of submerged/floating freshwater aquatic macrophytes / K.J. Ficken, B. Li, D.L. Swain, G. Eglinton // Organic Geochemistry. - 2000. V. 31. - P. 745-749.
42. Bowles J.F.W., Bowles J.H., Gize A.P. $\mathrm{C}_{14-22} \mathrm{n}$-alkanes in soil from the Freetown layered intrusion, Sierra Leone: products of Pt catalytic breakdown of natural longer chain n-alkanes? // Minerals. - 2018. V. 8. - Iss. 3. Article number: 105. DOI: 10.3390/min8030105.

43. Потурай В.А. Органическое вещество в холодных подземных водах районов азотных терм Приамурья // Региональные проблемы. - 2016. - Т. 19. - № 4. - С. 59-66.

44. Изменение состава битуминозных компонентов низинного торфа при стимулированном микробном воздействии / Л.И. Сваровская, О.В. Серебренникова, М.А. Дучко, Е.Б. Стрельникова, И.В. Русских // Химия твердого топлива. 2017. - № 2. - C. 3-13. DOI: 10.7868/S0023117717020098.

45. Origins and transformations of dissolved organic matter in large Arctic rivers / K. Kaiser, M. Canedo-Oropeza, R. McMahon, R. Amon // Scientific Reports. - 2017. - V. 7. - Article number: 13064.

46. Simoneit B.R.T. A review of biomarker compounds as source indicators and tracers for air pollution // Environmental science and pollution research international. - 1999. - V. 6. - № 3. P. $159-169$.

47. Peters K.E., Walters C.C., Moldowan M.J. The biomarker guide. Cambridge: Cambridge university press, 2005. - V. 1-2. - 1155 p.

48. Influence of peat formation conditions on the transformation of peat deposit organic matter / O.V. Serebrennikova, E.B. Strelnikova, Yu.I. Preis, M.A. Duchko // IOP Conf. Series: Earth and Environmental Science. - 2015. - V. 27. - Aticle number: 012036. DOI: 10.1088/1755-1315/27/1/012036.

49. Vertical distribution of organic compounds in the bottom sediments of two steppe lakes in southern Siberia / O.V. Serebrennikova, I.V. Russkikh, E.B. Strel'nikova, E.A. El'chaninova, P.B. Kadychagov // Water resources. - 2017. V. 44. - № 5. - P. 774-783.

50. Хант Д. Геохимия и геология нефти и газа. - М.: Мир, 1982. $704 \mathrm{c}$.

51. Margesin R., Schinner F. Biomediation (natural attenuation and biostimulation) of diesel-oil-contaminated soil in an alpineglacier skiing area // Applied and environmental microbiology. - 2001. № 67. - P. 3127-3133. DOI: 10.1128/AEM.67.7.3127-3133.2001.

52. Hidrocarbon biodegradation and soil microbial community response to repeated oil exposure / P.F. Greenword, S. Wibrow, S.J. George, M. Tibbett // Organic Geochemistry. - 2009. № 40. - P. 293-300.

53. Логинова Е.В., Лопух П.С. Гидроэкология: курс лекций. Минск: БГУ, 2011. - 300 с.

54. Исследование характеристик и минерального состава торфа Томской области применительно к энергетическому использованию / К.Т. Ибраева, Ю.О. Манаев, Р.Б. Табакаев, Н.А. Языков, А.С. Заворин // Известия Томского политехнического университета. Инжиниринг георесурсов. - 2019. T. 330. - № 1. - C. 191-200.

Поступила 08.10.2019 г.

\section{Информация об авторах}

Иванова И.С., кандидат геолого-минералогических наук, старший научный сотрудник лаборатории гидрогеохимии и геоэкологии Томского филиала Института нефтегазовой геологии и геофизики им. А.А. Трофимука СО РАН.

Савичев О.Г., доктор географических наук, профессор отделения геологии Инженерной школы природных ресурсов Национального исследовательского Томского политехнического университета.

Cолдатова E.A., кандидат геолого-минералогических наук, старший научный сотрудник Института геохимии и аналитической химии им. В.И. Вернадского РАН.

Наливайко Н.Г., кандидат геолого-минералогических наук, доцент отделения геологии Инженерной школы природных ресурсов Национального исследовательского Томского политехнического университета.

Корнеев Д.С., кандидат химических наук, старший научный сотрудник Института нефти и газа Югорского государственного университета.

Гусева Н.В., доктор геолого-минералогических наук, заведующая кафедрой-руководитель отделения геологии Инженерной школы природных ресурсов Национального исследовательского Томского политехнического университета.

Смирнова Н.А., инженер-исследователь лаборатории геологии месторождений нефти и газа Инженерной школы природных ресурсов Национального исследовательского Томского политехнического университета. 
UDC 556.531.4:550.84.094

\section{CONDITIONS OF TRANSFORMATION OF MUNICIPAL WASTEWATER IN BOG ECOSYSTEMS (ON THE EXAMPLE OF OBSKOE BOG, WESTERN SIBERIA)}

\author{
Irina S. Ivanova 1 \\ IvanovalS_1986@mail.ru
}

\author{
Oleg G. Savichev², \\ OSavichev@mail.ru
}

Evgeniya A. Soldatova ${ }^{3}$, 2a61@mail.ru

\author{
Dmitry S. Korneev4, \\ mitay2580@mail.ru
}

Natalia V. Guseva², gusevanv@tpu.ru

Natalia A. Smirnova², smirnova@hw.tpu.ru

Nina G. Nalivayko², nng@tpu.ru

1 Tomsk branch of the Trofimuk institute of petroleum geology and geophysics of Siberian branch of Russian academy of sciences, 4, Academichesky avenue, Tomsk, 634055, Russia.

2 National Research Tomsk Polytechnic University, 30, Lenin avenue, Tomsk, 634050, Russia.

3 Vernadsky Institute of Geochemistry and Analytical Chemistry of Russian Academy of Sciences, 19, Kosygina street, Moscow, 119991, Russia.

4 Yugra State University,

16, Chekhov street, Khanty-Mansiysk, 628012, Russia.

Relevance. The issue of conservation and use of bogs is very urgent throughout the world, including Western Siberia, where a large part of hydrocarbon raw materials in the Russian Federation are extracted. It is accompanied by environmental changes, which concern bog ecosystems. This determines the relevance to develop a methodology and technology for environmental protection of bog ecosystems subjected to anthropogenic impact. For this methodology, a reliable assessment of changes in the bog ecosystem under the influence of the influx of substances of anthropogenic origin is required.

The aim of the research is to analyze and interprete the conditions of municipal wastewater transformation in lowland bog on the example of typical Western Siberian eutrophic bog Obskoe.

Methods. Chemical and microbiological composition of natural waters were analyzed in the Fundamental research laboratory of hydrogeochemistry (TPU), which is registered in the System of analytical laboratories of Gosstandart of Russia. To carry out the comprehensive chemical analysis the authors applied the traditional methods. The microbiological analysis was carried out after sampling, basically during the day. The samples had been kept in the cooling bag until they were delivered to the laboratory. To identify the microorganisms the authors used liquid and firm elective nutrient mediums. The trace elements were determined by inductively coupled plasma massspectrometry (ICP-MS). The structural-group composition of dissolved organic matter was determined by gas chromatography-mass spectrometry method. Statistical methods and mathematical modeling were applied to study hydrogeochemical processes.

Results and conclusions. It was found that the bog waters are characterized by high contents (relative to maximum permissible concentrations) of organic matters, products of their transformation, as well as some chemical elements, which are able to form complexes with organic matters. Among the dissolved organic compounds esters, carboxylic acids are dominated in the bog waters. They contribute not only to accumulation of certain elements (Ni, Ba) in the waters but to development of microorganisms as well. It was shown, that accumulation of the elements entering the bog waters from municipal wastewater of Melnikovo settlement takes place mainly on the boundary of active and inert horizons of the peat deposit. It was shown, that the discharge of municipal wastewater to the bog near Melnikovo settlement does not significantly change the chemical composition of the bog waters, and anthropogenic impact is limited by microbiological and geochemical conditions of the bog. Based on the data obtained, it was proposed to adjust environmental measures to limit the expansion of boggy areas by the increase in forest land due to drainage reclamation and the addition of nitrogen and calcium compounds that are part of municipal wastewater and wastewater of oil and gas industry.

Key words: Wastewater, chemical composition, development of methodology and technologies, self-treatment of municipal wastewater, Obskoe lowland bog.

The research was financially supported by the RFBR grants no. 18-55-80015, 17-05-00042, 19-05-00290. The study of geochemical barrier formation in the area of the Ob Bog was carried out at the expense of grant RSF no. 19-77-00014.

\section{REFERENCES}

1. Markov V.D., Olenin A.S., Ospennikova L.A., Skobeeva E.I., Khoroshev P.I. Torfyanye resursy mira [Peat resources of the world]. Moscow, Nedra Publ., 1988. 383 p.
2. Meng W., He M., Hu B., Mo X., Li H., Liu B., Wang Zh. Status of wetlands in China: A review of extent, degradation, issues and recommendations for improvement. Ocean \& Coastal Management, 2017, vol. 146, pp. 50-59. Available at: http://dx.doi.org/10.1016/ j.ocecoaman.2017.06.003 (accessed 1 October 2019). 
3. Jianga W., Lv J., Wang C., Chen Zh., Liu Y. Marsh wetland degradation risk assessment and change analysis: A case study in the Zoige Plateau, China. Ecological Indicators, 2017, vol. 82, pp. 316-326. Available at: http://dx.doi.org/10.1016/j.ecolind. 2017.06.059 (accessed 1 October 2019).

4. Hu S., Niu Zh., Chen Y., Li L., Zhang H. Global wetlands: Potential distribution, wetland loss, and status. Science of the Total Environment, 2017, vol. 586, pp. 319-327. DOI: 10.1016/j.scitotenv.2017.02.001.

5. Neustadt M.I. Bolota Ob-Irtyshskogo mezhdurechya [Bogs of the Ob-Irtysh interfluves]. Prirodnye usloviya osvoyeniya mezhdurechya Ob-Irtysh [Natural conditions for the development of the Ob-Irtysh interfluve]. Moscow, AS of USSR, Institute of Geography, 1972. pp. 322-346.

6. Liss O.L., Abramova L.I., Avetov N.A. Bolotnye sistemy Zapadnoy Sibiri i ikh prirodookhrannoe znachenie [Bog of Western Siberia and their conservation value]. Tula, Grif i Ko Publ., 2001. $584 \mathrm{p}$.

7. Pologova N.N., Lapshina E.D. Nakoplenie ugleroda v torfyanykh zalezhakh Bolshogo Vasuganskogo bolota [Carbon accumulation in peat bog deposits of the Great Vasyugan]. Bolshoe Vasuganskoe boloto. Sovremennoe sostoyanie $i$ protsessy razvitiya [Big Vasyugan bog. Current status and development]. Tomsk, Institute of Atmospheric Optics SB RAS Publ., 2002. pp. 174-179.

8. Minayeva T., Bleuten W., Sirin A., Lapshina E.D. Eurasian Mires of the Southern Taiga Belt: Modern Features and Response to Holocene Palaeoclimate. Wetlands and Natural Resource Management. Ecological Studies. Vol. 190. Eds. J.T.A. Verhoeven, B. Beltman, R. Bobbink, D.F. Whigham. Berlin; Heidelberg, Springer-Verlag, 2006. pp. 315-341.

9. Kulkov M.G., Korzhov Yu.V., Artamonov V.Yu., Uglev V.V. Structure and features of changing in time of organic substance water-soluble complex in oil polluted water environment. Bulletin of the Tomsk Polytechnic University, 2012, vol. 320, no. 1, pp. 193-199. In Rus.

10. Altunina L.K., Svarovskaya L.I., Yaschenko I.G., El'chaninova E.A. Ecological state of water bodies in middle $\mathrm{Ob}$ oil-producing areas. Petroleum Chemistry, 2017, vol. 57, no. 5, pp. 452-456. In Rus. DOI: $10.7868 / \mathrm{S} 0028242117020034$.

11. Tong Yi., Mayera B.K., McNamara P.J. Adsorption of organic micropollutants to biosolids-derived biochar: estimation of thermodynamic parameters. Environmental Science: Water Research \& Technology, 2019, vol. 6, pp. 1132-1144. DOI: 10.1039/C8EW00854J.

12. Shishov V.A., Shemetov V.Yu., Ryabchenko V.I., Parfenov V.P. Okhrana okruzhayushchey sredy $v$ territorialnom ZapadnoSibirskom komplekse [Environmental protection in the territorial West Siberian complex]. Moscow, VNIIOENG Publ., 1988. 50 p.

13. Inisheva L.I., Kobak K.I., Inishev N.G. Paludification on Vasyugan mire contemporary. Problems of Ecology, 2017, vol. 10, no. 2, pp. 105-110. DOI: 10.1134/S1995425517020044.

14. Bleuten W., Lapshina E., Ivens W., Shinkarenko V., Wiersma E. Ecosystem recovery and natural degradation of spilled crude oil in peat bog ecosystems of West Siberia. International Peat Journal, 1999, no. 9, pp. 73-82.

15. Metodika razrabotki normativov dopustimykh sbrosov veshchestv $i$ mikroorganizmov $v$ vodnyye obyekty dlya vodopolzovateley [Methodology for developing standards for permissible discharges of substances and microorganisms into water bodies for water users]. 17.12.2007. № 333. Moscow, Ministry of Nature Resources of Russia, 2018. 35 p.

16. GOST 21123-85. Torf. Terminy i opredeleniya [State Standard 21123-85. Peat. Terms and definitions]. Moscow, Izdatelstvo standartov, $1985.85 \mathrm{p}$.

17. Savichev O.G., Guseva N.V., Kupriyanov E.A., Skorokhodova A.A., Akhmed-Ogly K.V. Chemical Composition of the Ob Bog (West Siberia) and its Spatial Variations under the Influence of the Discharge of Pollutants. Bulletin of the Tomsk Polytechnic University, 2013, vol. 323, no. 1, pp. 168-172. In Rus.

18. Torfyanye mestorozhdeniya Tomskoy oblasti [Peatland of Tomsk region]. Eds. Ya.N. Zadunaysky, I.N. Kazakov, V.D. Markov. Moscow, Geoltorforazvedka Publ., 1971. 306 p.

19. Schipper A.M., Zeefat R., Tanneberger F., van Zuidam J.P., Hahne W., Schep S.A., Loos S., Bleuten W., Joosten H., Lapshina E.D., Wassen M.J. Vegetation characteristics and ecohydrological processes in a pristine mire in the Ob River valley
(Western Siberia). Plant Ecology, 2007, vol. 193, pp. 131-145. DOI: 10.1007/s11258-006-9253-x.

20. Savichev O.G., Mazurov A.K., Rudmin M.A., Khvashchevskaya A.A., Dauletova A.B. Changes in chemical composition of acid extracts on depth of peat deposit of the Vasyugan mire ecological systems (Western Siberia). Bulletin of the Tomsk Polytechnic University. Geo Assets Engineering, 2018, vol. 329, no. 9, pp. 101-116. In Rus.

21. Mezhibor A.M., Arbuzov S.I., Arkhipov V.S. Trace elements in peat bogs of Tomsk region (South Siberia, Russia). Energy exploration \& exploitation, 2013, vol. 31, no. 4, pp. 629-644.

22. Arbuzov S.I., Maslov S.G., Finkelman R.B., Mezhibor A.M., Ilenok S.S., Blokhin M.G., Peregudina E.V. Modes of occurrence of rare earth elements in peat from Western Siberia. Journal of Geochemical Exploration, 2017, no. 10, pp. 1-22. Available at: https://doi.org/10.1016/j.gexplo.2017.10.012 (accessed 12 October 2017).

23. Ekologiya mikroorganizmov [Ecology of microorganisms]. Ed. by A.I. Netrusov. Moscow, AKADEMA Publ., 2004. 267 p.

24. Golovchenko A.V., Sannikova Yu.V., Dobrovol'skaya T.G., Zvyagintsev D.G. The saprotrophic bacterial complex in the raised peat bogs of western Siberia. Microbiology, 2005, vol. 74, no. 4, pp. 471-476.

25. MUK 4.1. 663-97. «Metodicheskie ukazaniya. Opredelenie massovoy kontsentratsii organicheskikh soyedineniy $v$ vode metodom khromato-mass-spektrometrii» [MUK 4.1. 663-97. Methodical instructions. Determination of mass concentration of organic compounds in water by chromatography-mass spectrometry]. Moscow, Ministry of Health of Russia Publ., 1997. 4 p.

26. Soniassy R., Sandra P., Schlett C. Water analysis: organic micropollutants. Germany, Hewlett-Packard Company, 1994. 278 p.

27. Krasnova T.A., Timoshchuk I.V., Gorelkina A.K., Dugarjav J. The Choice of sorbent for adsorption extraction of chloroform from drinking water. Foods and Raw Materials, 2017, vol. 5, no. 2, pp. 189-196. DOI: 10.21179/2308-4057-2017-2-189-196.

28. Schmidt T.C. Recent trends in water analysis triggering future monitoring of organic micropollutants. Analytical and Bioanalytical Chemistry, 2018, vol. 410, no. 17, pp. 3933-3941. Available at: https://doi.org/10.1007/s00216-018-1015-9 (accessed 1 October 2019).

29. Orlov D.S. Khimiya pochv [Chemistry of soils]. Moscow, Moscow University Publ. house, 1985. 376 p.

30. Wilkinson G.M., Pace M.L., Cole J.J. Terrestrial dominance of organic matter in north temperate lakes. Global Biogeochemical Cycles, 2013, vol. 27, pp. 1-9.

31. Salas D., Borrull F., Fontanals N., Marcé R.M. Hydrophilic interaction liquid chromatography coupled to mass spectrometry-based detection to determine emerging organic contaminants in environmental samples. Trends in analytical chemistry, 2017, vol. 94, pp. 141-149. Available at: https://doi.org/10.1016/j.trac. 2017.07.017 (accessed 1 October 2019).

32. Posobie po opredeleniyu raschetnykh gidrologicheskikh kharakteristik [The manual by definition of hydrological characteristics]. Eds. A.V. Rozhdestvensky, A.G. Lobanova. Leningrad, Gidrometeoizdat Publ., 1984. 448 p.

33. Savichev O.G., Mazurov A.K., Rudmin M.A., Shakhova N.E., Sergienko V.I., Semiletov I.P. Mechanisms of accumulation of chemical elements in a peat deposit in the eastern part of Vasyugan swamp (West Siberia). Doklady earth sciences, 2019, vol. 486, pp. 568-570. DOI: 10.1134/S1028334X19050258.

34. Turov Yu.P., Pirogova I.D., Guznyaeva M.Yu., Ermashova N.A. Organic impurities in natural waters near Strezhevoy. Water resources, 1998, vol. 25, no. 4, pp. 455-461. In Rus.

35. Kontorovich A.E., Shvartsev S.L., Zuev V.A., Rasskazov N.M., Turov Y.P. Organic trace contaminants in fresh natural waters from the drainage basins of Tom' and Upper Ob' rivers. Geochemistry International, 2000, vol. 38, no. 5, pp. 480-490.

36. Gorbov S.N., Bezuglova O.S. Specific features of organic matter in urban soils of Rostov-on-Don. Eurasian Soil Science, 2014, vol. 47 , no. 8, pp. 792-800.

37. Panicheva L.P., Moiseenko T.I., Kremleva T.A., Volkova S.S. Formation of the composition of organic substances in small lakes of Western Siberia. Bulletin of the Tyumen State University. Ecology and nature management, 2015, vol. 1, no. 1, pp. 151-163. In Rus. 
38. Efremova T.T., Efremov S.P., Kalacheva G.S. Organic trace components extractable by chloroform from swamp and river waters in the middle Ob basin. Water resources, 2018, vol. 45, no 5, pp. 757-766. DOI: 10.1134/S0097807818050068.

39. Serebrennikova O.V., Strelnikova E.B., Russkikh I.V., Kharanzhevskaya Yu.A., Voistinova E.S. Seasonal dynamics of the distribution of organic compounds in the marsh waters of the southern taiga (Western Siberia). Chemistry in the interests of sustainable development, 2019, no. 27, pp. 65-72. In Rus.

40. Tissot B., Welte D. Obrazovanie i rasprostranenie nefti $i$ gaza [Formation and distribution of oil and gas]. Moscow, Mir Publ., $1981.501 \mathrm{p}$.

41. Ficken K.J., Li B., Swain D.L., Eglinton G. An n-alkane proxy for the sedimentary input of submerged/floating freshwater aquatic macrophytes. Organic Geochemistry, 2000, vol. 31, pp. 745-749.

42. Bowles J.F.W., Bowles J.H., Gize A.P. $\mathrm{C}_{14-22}$ n-alkanes in soil from the Freetown layered intrusion, Sierra Leone: products of $\mathrm{Pt}$ catalytic breakdown of natural longer chain n-alkanes? Minerals, 2018, vol. 8, no. 3, article number 105. DOI: 10.3390/min8030105

43. Poturay V.A. Organic matter in underground waters of the Amur region geothermal fields. Regional problems, 2016, vol. 19, no. 4, pp. 59-66. In Rus.

44. Svarovskaya L.I., Serebrennikova O.V., Duchko M.A., Strel'nikova E.B., Russkikh I.V. Changes in the composition of the bituminous components of valley peat under stimulated microbial action. Solid Fuel Chemistry, 2017, vol. 51, no 2, pp. 67-77. DOI: 10.3103/S0361521917020094.

45. Kaiser K., Canedo-Oropeza M., McMahon R., Amon R. Origins and transformations of dissolved organic matter in large Arctic rivers. Scientific Reports, 2017, vol. 7, article number: 13064.

46. Simoneit B.R.T. A review of biomarker compounds as source indicators and tracers for air pollution. Environmental science and pollution research international, 1999, vol. 6, no. 3, pp. 159-169.
47. Peters K.E., Walters C.C., Moldowan M.J. The biomarker guide. Cambridge, Cambridge university press, 2005. Vol. 1-2, 1155 p.

48. Serebrennikova O.V., Strelnikova E.B., Preis Yu.I., Duchko M.A. Influence of peat formation conditions on the transformation of peat deposit organic matter. IOP Conf. Series: Earth and Environmental Science, 2015, vol. 27, no. 012036. DOI: 10.1088/17551315/27/1/012036.

49. Serebrennikova O.V., Russkikh I.V., Strel'nikova E.B., El'chaninova E.A., Kadychagov P.B. Vertical distribution of organic compounds in the bottom sediments of two steppe lakes in southern Siberia. Water resources, 2017, vol. 44, no. 5, pp. 774-783.

50. Khunt D. Geokhimiya i geologiya nefti i gaza [Geochemistry and geology of oil and gas]. Moscow, Mir Publ., 1982. 704 p.

51. Margesin R., Schinner F. Biomediation (natural attenuation and biostimulation) of diesel-oil-contaminated soil in an alpineglacier skiing area. Applied and environmental microbiology, 2001, no. 67 pp. 3127-3133. DOI: 10.1128/AEM.67.7.3127-3133.2001.

52. Greenword P.F., Wibrow S., George S.J., Tibbett M. Hidrocarbon biodegradation and soil microbial community response to repeated oil exposure. Organic Geochemistry, 2009, no. 40, pp. 293-300.

53. Loginova E.V., Lopukh P.S. Gidroekologiya: kurs lektsiy [Hydroecology: course of lectures]. Minsk, Belarusian State University Publ., 2011. 300 p.

54. Ibraeva K.T., Manaev Yu.O., Tabakaev R.B., Yazykov N.A., Zavorin A.S. Research of characteristics and mineral composition of peat of the Tomsk region relating to energy use. Bulletin of the Tomsk Polytechnic University. Geo Assets Engineering, 2019, vol. 330 , no. 1 , pp. 191-200.

Received: 8 October 2019.

\section{Information about the authors}

Irina S. Ivanova, Cand. Sc., senior researcher, Tomsk branch of the Trofimuk institute of petroleum geology and geophysics of Siberian branch of Russian academy of sciences.

Oleg G. Savichev, Dr. Sc., professor, National Research Tomsk Polytechnic University.

Evgeniya A. Soldatova, Cand. Sc., senior researcher, Vernadsky Institute of Geochemistry and Analytical Chemistry of Russian Academy of Sciences.

Nina G. Nalivayko, Cand. Sc., associate professor, National Research Tomsk Polytechnic University.

Dmitry S. Korneev, Cand. Sc., senior researcher, Yugra State University.

Natalia V. Guseva, Dr. Sc., Head of the Division for Geology, National Research Tomsk Polytechnic University. Natalia A. Smirnova, research engineer, National Research Tomsk Polytechnic University. 